\title{
A Puzzle from Elsewhere: Against the Standard Account of Elsewhere
}

\author{
- Morgan Luck -
}

\begin{abstract}
The standard account of elsewhere is that it is any place that isn't here. In this paper I argue against this account by demonstrating that (given some plausible assumptions) it results in a contradiction. In its place I offer a modified account of elsewhere; where a place can only be elsewhere if it is in the same type of space as here.
\end{abstract}

Keywords: elsewhere; here; space; indexical; puzzle.

Published online: 30 March 2020

\section{Introduction}

The standard account of elsewhere is that it is any place that isn't here. For example, if here is in the café I'm sitting, any place that isn't in this café is elsewhere. I will argue against the standard account, and offer an alternative account.

\section{First objection to the standard account}

So, what is wrong with the standard account? Some might think the standard account is false because it seems to give rise to a contradiction. ${ }^{1}$ To illustrate this, consider the following case:

I'm here on Earth. So, as Pluto is a place that isn't here, Pluto is elsewhere according to the standard account.

So, the standard account seems to supports proposition 1 of the set below:

1. Pluto is elsewhere.

2. It is possible for me (right now) to go elsewhere.

3. It is not possible for me (right now) to go to Pluto.

\footnotetext{
Morgan Luck

Associate Professor in Philosophy

School of Humanities and Social Sciences

Charles Sturt University

Waga Waga, Building 26

Australia

moluck@csu.edu.au

1 My thanks to a blind reviewer for this possible objection.
} 
This seems like an inconsistent set, which might lead some to reject 1 , and in turn the standard account which supports it. However, the standard account can resist this attack. This is because 2 might be understood in two different ways:

$2^{\mathrm{A}}$ It is possible for me (right now) to go some places which are elsewhere.

$2^{B}$ It is possible for me (right now) to go all places which are elsewhere.

If we interpret 2 as $2^{\mathrm{A}}$ the inconsistency disappears (and with it this objection). If we interpret 2 as $2^{\mathrm{B}}$ then 2 seems false (especially given 1 and 3 ). So, this objection fails. Let us now consider a second objection to the standard account.

\section{Second objection to the standard account}

Some might think the standard account is false because it seems to give rise to a different inconsistency. ${ }^{2}$ To illustrate this, consider the following case:

A US general in Washington, whist pointing to Fallujah on a map of Iraq says, "Our troops are under heavy fire here. So, move them elsewhere immediately!"

One might argue that, as the general is located in Washington, his here is Washington. In which case, Fallujah will be elsewhere according to the standard account (as Fallujah is, for the general, a place that is not here). But then it seems the general's command to move the troops elsewhere could be fulfilled by moving them from Fallujah to Fallujah.

So, the standard account seems to support proposition 4 of the set below:

4. Fallujah is elsewhere.

5. Fallujah is not elsewhere.

However, common sense supports 5, and as the set is inconsistent this may lead some to reject 4; and in turn the standard account which supports it. However, the standard account can again resist this attack. This is because the "here" in this case is not picking out the general's location, but instead the location of the troops to which the general is pointing. This may lead us to employ a more nuanced account of "here" (one that doesn't merely pick out the location of the agent uttering "here"); but it doesn't lead us to reject the standard account of elsewhere. So, this objection fails. Let us now consider a third objection to the standard account.

\section{Third objection to the standard account}

I argue that (together with some plausible assumptions) the standard account gives rise to a different contradiction. To demonstrate this, consider the following case:

\footnotetext{
${ }^{2}$ My thanks to a blind reviewer for this possible objection.
} 
Let us assume that here is in the café I'm sitting, and a particular online chatroom is a place (albeit an online place) that isn't in this café.

Given these two assumptions, and the standard account, we can construct the following argument:

6. Any place that isn't here is elsewhere.

7. Here is in this café.

8. The chatroom isn't in this café.

So,

9. The chatroom is a place that is elsewhere.

This conclusion is puzzling, but not obviously so. To bring out the puzzle, let us now add to the case above:

Imagine I am waiting for two friends in the café: Wylie and Daniel. Daniel turns up and asks "Where is Wylie?", to which I reply "Elsewhere." However, unbeknownst to me Wylie is actually in the café; I haven't noticed him as he is hunched behind his laptop, chatting to people online in the aforementioned chatroom.

It seems clear that my assertion that Wylie is elsewhere is false; and here is an argument to support this:

6. Any place that isn't here is elsewhere.

7. Here is in this café.

10. Wylie is in this café.

So,

11. Wylie is not elsewhere.

But, puzzlingly, here is an argument for the opposite conclusion:

9. The chatroom is a place that is elsewhere.

12. Wylie is in the chatroom.

So,

13. Wylie is elsewhere.

So, something has gone wrong somewhere.

\section{The modified standard account}

To solve the puzzle, I suggest we play closer attention to the type of space here is located in (or, as Predelli [1998] puts it, the context of the location). To illustrate this, consider the following case: 
Upon becoming the richest person alive Steve exclaims "I' $m$ at the top of the heap," and with disdain he regards the rest of us and adds, "and you are all...elsewhere."

Steve's here is not in a spatiotemporal space (unlike the here inside the café). Rather, it is in a wealth space; a one-dimensional space, where the richest are furthest in one direction, and the poorest are furthest in the other.

In saying that "I' $m$ at the top of the heap, and you are all...elsewhere", Steve is asserting that (a) his here is the furthest in the rich direction of the wealth space, and (b) no other person in the wealth space occupies this location. The point to note is that Steve's here and, more importantly, his elsewhere, refer to places, and only places, in the wealth space. Here and elsewhere are indexed exclusively to the same type of space.

Given this, I suggest the standard account of elsewhere be replaced with the following:

14. A place is elsewhere if, and only if, it is a place that isn't here, but is in the same type of space as here.

So, take a type of space (such as, a spatiotemporal space [where you can find my café], an online space [where you can frequent a virtual chatroom], or a wealth space [where you can look "down" upon those poorer than you]), and note where you are in this space (your here); elsewhere is any place in this same type of space which isn't where you are.

What does all this tell us? It tells us that elsewhere is not simply any place that isn't here (as the standard account holds). Being a place that isn't here is just one necessary condition of being elsewhere. It must also be a place in the same type of space as here. So, Wylie isn't both elsewhere and not elsewhere. In respect to my here (in the café, which is a spatiotemporal space) Wylie is not elsewhere. It is true that Wylie is also in the chatroom; but the chatroom fails to qualify as elsewhere (in respect to my here). This point can be presented as follows:

7. Here is in this café.

14. A place is elsewhere if, and only if, it is a place that isn't here, but is in the same type of space as here.

15. The café is in a spatiotemporal type of space, and the chatroom is not.

So,

16. The chatroom is a place that is not elsewhere.

And if 16 is true, 9 is false. Which then makes the argument from $9 \& 12$ to 13 unsound. Likewise, if 16 is true, 6 is false. Which then makes the argument from 6,7 \& 8 to 9 unsound. And so, the puzzle dissolves.

\section{First objection to the modified standard account}


One possible objection to the modified account of elsewhere concerns cases involving a here seemingly located in multiple types of spaces. To illustrate this concern, consider the following case:

Emma is meeting Suzanne to play Pokémon Go together. Pokémon Go is a computer game for mobile devices that is sensitive to real world locations. Emma plans to meet Suzanne in Central Park (a location in New York) and at a particular pokestop (a location in the game world). At the meeting time she texts Suzanne asking, "Are you here?" Suzanne has arrived in Central Park, but she has yet to log into the game, and so is not at the pokestop.

The modified account might seem to struggle with this case, as Emma seems to be using "here" to refer to a place that spans two different types of spaces: somewhere that is in a game space and in a physical space. So, given this, is Suzanne elsewhere?

Reconsider the modified account:

14. A place is elsewhere if, and only if, it is a place that isn't here, but is in the same type of space as here.

Given Suzanne is not here (i.e. in Central Park at the pokestop), whether she is elsewhere will depend on whether Suzanne is in the same type of space as here. According to the modified account, if she is, then she is elsewhere, otherwise she is not. However, given that there are two types of spaces involved (Suzanne is in a physical space, but not in the game space), the modified account seems to have difficulty with this question.

This difficulty disappears once we allow that a type of space may be hybrid. The type of space that Emma is planning to meet Suzanne in is not a wholly physical one, nor is it wholly a game space. It is a hybrid - let's call it a physi-game space. Once we consider this physi-game space as the type of space that Emma is planning to meet Suzanne, the modified account is able to deliver the following answer: Suzanne is not here (because she is not at the pokestop), but she is also not elsewhere (because she is not in the same type of place as here - the physi-game space [for, although she is in physical space, she has not yet logged into the game space]).

At first this might seem like a bad result for the modified account. For how can something be both not here, and also not elsewhere? However, this result is far more common than we might at first think. For example, as I don't have a dog, my dog is neither here, nor is it elsewhere. Suzanne, like my dog, is non-existent in the type of space we are referring to, the physi-game space. She is neither here (at the Central Park/pokestop location), nor is she elsewhere (that is, anywhere else in the physi-game space). Thus, the modified account delivers the right result.

\section{Second objection to the modified account}


A possible second objection to the modified account arises from an oddness that results when departing from the standard account. ${ }^{3}$ To illustrate this oddness, consider the following case:

A mathematical Platonist, who believes all numbers are located in a non-physical space (the platonic realm), is challenged by her student with the following assertion:

"Two is here, as it is instantiated by the two of us."

"No." the Platonist responds, "Two is elsewhere".

Assuming the "here" being referred to by the student is a physical type of space, and the Platonist's theory is correct (in that two is neither here, nor in any other physical location), it follows from the modified account that two not elsewhere either (as two is in a different type of space to here). So, the Platonist's assertion that "Two is elsewhere" and the modified account are at odds - a result that might lead some to reject the modified account. So, bullets may need to be bitten. Let us consider their caliber.

Proponents of the modified account must correct the Platonist's assertion that two is elsewhere. The Platonist's response should have been "No. Two is neither here, nor is it elsewhere. It is located in an entirely difference space". Why is this a bullet to bite? Because, as we commonly have in mind the standard account, suggesting something is located in a different type of space, whilst denying it is elsewhere, seems odd. It rubs against our current understanding.

In contrast, proponents of the standard account need to deal with the problems highlighted earlier. Namely, as illustrated in the third objection to the standard account (the café case), that something can be both elsewhere and not elsewhere; a logical contradiction.

So, the question is, which is the bigger bullet to bite? The particular oddness resulting from the modified account (as illustrated by the Platonist case); or a contradiction (as illustrated by the café case).

Without a defense of the standard account (or an alternative modification) I would suggest it is better to deny the contradiction and live with the (potentially temporary $)^{4}$ oddness. $^{5}$

\section{References}

Predelli S. (1998), “I Am Not Here Now,” Analysis 58 (2): 107-115.

\footnotetext{
3 My thanks to a blind reviewer for this possible objection.

4 Presumably, if "elsewhere" was eventually understood in line with the modified account, the oddness resulting from it jarring with the standard account would dissipate.

${ }^{5}$ My thanks to the blind reviewers and Emma Rush and Steve Clarke for their help on this paper.
} 